mechanism, each may have its distinct effector mechanism ending, the one perhaps on skin cell and the other perhaps on arteriole. These possibilities are all in accord with the facts as these are known, and we should be justified, therefore, in regarding the two series of nerve paths as separate. The general conception would be similar to that which we take in the case of pilomotor and sudorific nerves. Here also are two series of nerves following similar branching axonic paths in the skin; but they arise differently, end in connexion with different cells, and produce for that reason dissimilar effects; but both belong to the same general system, the system of sympathetic nerves.

[A full List of References will be given at the conclusion of the second lecture.]

\section{FOOD AND NUTRITION *}

BY

\section{E. P. CATHCART, C.B.E., M.D., F.R.S. \\ Regius Professor of Physiology, University of Glasgow}

[In the opening part of his lecture Professor Cathcart gave a brief review of the food side of the problem in the light of present-day knowledge, stressing the great gaps in this knowledge that still exist.]

When we turn to the question of nutrition we enter a realm which is largely speculative. There are those who hold that the state of nutrition is definitely, and by inference only, an index of the adequacy of the diet. - Personally, in common with many others, I believe the state of nutrition indicates much more than the adequacy of the diet.

We all believe that we can decide, with a certain degree of assurance, whether the state of nutrition of a given individual is good or not, and yet, at the same time, if we were asked to state why we reached our degree of certainty we would be hard put to it to give an explicit answer. In other words, we do realize that in this state there is something more involved than mere physical attributes like stature, bulk, bloom of skin, gloss of hair, and so on; that there are also intangible psychic factors which may be summarized in terms like "alertness," "fitness," " aliveness." We judge normally by the "wholeness" of the picture. It is a question of the primacy of the whole over the separate parts. We arrive at our assessment by a kind of intuition based on our own particular experience.

I have no doubts in my own mind that the term "nutrition" should be retained for a wide conception of the state of well-being which characterizes the individual who is both physically and psychically sound. Those who wish to refer only to the influence of focd on the body, who, in other words, wish to limit their conception, would have quite a useful and sufficient word in alimentation. They could speak then of states of good and bad alimentation-that is, the states resulting from the ingestion of adequate or inadequate diets. If the words were not quite so exotic we might adopt, for differentiation, the words used by the Greeks-eusitia and eutrophia. I understand from my classical colleagues that the Greeks, more precise in the use of words than we are, differentiated between well-fed (eusitia) and wellnourished (eutrophia). These words have the additional

* Sir Charles Hastings Lecture (abridged) given under the auspices of the British Medical Association in the McLellan Galleries, Glasgow, February 23, 193 ? advantage that a negative form dysitia and dystrophia may be used. I believe it must be accepted that when we speak of, say, excellent nutrition (eutrophia) and malnutrition (dystrophia) we are speaking of clinical syndromes, because in everyday practice it is found there is no physical yardstick by which the degree of nutrition can be measured. Moreover, every medical man realizes the extent to which physical conditions like weight can be dominated by psychical states, and how, for instance, an immobilized limb can atrophy despite an adequate food intake. It is quite clear to me at least that when we use that much-abused term "malnutrition" we are referring to a state of the bcdy which is not solely dependent on the inadequacy of the food intake; that many other factors like lack of sleep, of play, of fresh air, of happiness, absence of worry, and so on play parts in the determination of the condition. It is admitted, of course, that an adequate supply of proper food is absolutely essential, but food alone cannot work miracles.

\section{"Malnutrition"}

I have stated that there is no measure by which the degree of "malnutrition" can be defined; hence it is not surprising that where each individual medical officer makes his own subjective judgement, a judgement which can be distorted by all manner of personal, but probably in the majority of cases unconscious, predilections, wide variance in the extent to which "malnutrition" is reported to exist in given areas is to be expected. Until some standard, some method, can be devised which will rule out these individual predilections no finality can be reached. It is not that the search for such a measure has been neglected. Repeated attacks have been made on the subject, and each time the examining committee has fallen back on the clinical findings.

The question of the extent of "malnutrition," be the cause what it may, has given rise in recent times to great debate, much of it extraordinarily itl informed. One of the greatest of statisticians in this country, Mr. Udny Yule, speaking recently on the fall which had taken place in the death rate, said:

"That such a change must mean a very great improvement in the condition of the poorer part of our population, which forms the great majority of it, seems to me obvious, and I think this cheering story deserves some special emphasis at present, when there is much talk, some of it sensible but some of it a bit lurid, and some of it-I think it is hardly too much to say-a little hysterical, on such matters as housing, unemployment, and nutrition. Some of it indeed is to me almost incredible, for if any large proportion of our population be as seriously undernourished as it is sometimes represented the existence of such low death rates becomes difficult to explain, and if unemployment were as grave a factor as is sometimes alleged it would be odd that unexampled unemployment should be accompanied by record low mortalities."

This comment receives support from the evidence collected by school medical officers, which, despite its variable quality, does not disclose the existence of much serious and widespread "malnutrition."

To my mind the comment of Mr. Udny Yule is just, timely, and proper. No one could be stupid enough to claim that all diets in this country are ideal when it is well known that many are faulty, but I do not believe they are so desperately bad as claimed by some writers. As Mendel said:

"There is no field of practical importance related to human well-being in which there is greater opportunity for dogmatism and quackery, for pseudo-science and unwarranted prescrip- 
tions and proscriptions, than in the domain of our daily diet."

The difficulty is that so many people think they are authorities on the subject of food and nutrition in general, and they do not hesitate to air their views, forgetting, or more often ignorant of, the number of problems, particularly quantitative ones, still unsolved. They forget, moreover, that in problems where the factors concerned are for the most part incapable of accurate measurement their knowledge about the subject must, as Kelvin pointed out long ago, be meagre and unsatisfactory. Under these conditions these would-be experts only too often darken counsel by words without knowledge.

\section{Indices of Nutrition}

As measures of the state of nutrition the indices commonly adopted are height and weight and the relation of these to age. Certainly both height and weight are capable of fairly accurate measurement. Weight as an index is, however, of very little value, as it is a wellrecognized fact that the capacity to put on weight varies considerably with the temperament and particular constitution of the individual child or adult. The thin wiry child is, indeed, from the medical point of view fitter and more resistant on the whole than the fat overfed child. Weight may be due to big heavy bones, to much muscle, or to excess fat.

More emphasis has rightly been laid on the height factor. The stunted growth of the child which has been brought up in a faulty environment of whatever nature is a well-recognized phenomenon. There is no question that when such children are removed to a good environment the improved physique which results is remarkable. These are established facts. But recently there has been an active drive to transfer this possibility of improved physique from the particular to the general, the inference being that the bulk of the general population would respond in like manner. In his presidential address to the British Association last year Sir Josiah Stamp gave currency to the following statement:

"It has been computed that a benevolent dictator could, at a relatively small expense, by applying our modern knowledge of diet, add some two inches to the average stature and seven or eight pounds to the average weight of the general population besides enormously increasing their resistance to disease."

I do not think anyone would question the ability of the so-called benevolent dictator to increase the body weight, but there might be a considerable measure of doubt as to whether all his efforts in the way of selected diet would add two inches to the average height and also increase enormously the resistance of the population to disease. I think it may be said it is generally believed that if it were possible to devise the perfect diet suited to the needs of each individual the resistance to disease might be increased so far as mortality is concerned but without much reduction in morbidity. Tuberculosis is the one disease to which there does seem to be fairly good evidence that a well-fed body is more resistant.

\section{Rate of Growth, and Ultimate Stature}

When we turn to the consideration of the possibility of increasing the average stature from a present average of approximately sixty-seven inches to sixty-nine inches the food supply of the benevolent dictator would have to contain some very stimulating ingredients, ingredients potent enough to defeat hereditary inertia. At the outset we must differentiate between rate of growth in the young and ultimate stature in the adult. Stature is not so subject to environmental influence as weight. It is much more static, it is an inborn character, determined more by heredity than environment. The hereditary influence has been stated to account for over 90 per cent. of stature. It is true there is a certain small amount of evidence to suggest that the Nordic races at least are gradually growing taller. Such deductions have in the main been drawn from the growth of both male and female students in certain American universities, yet, on the other hand, the authors of the volume on statistics relating to the great mass of recruits for the American Army in the late war are more cautious. They compared their data with the Army data of the Civil War some fifty years earlier, and found little apparent change in height, although there was a few pounds increase in weight. After due consideration of all the factors they inclined to the belief that the average stature in the United States had actually decreased by about one half-inch, due probably to the immigration of shorter races. The same view concerning the increase of height of the student class has been put forward in this country. Sir Arthur Keith holds, however, that "the evidence so far leads us to believe that our present stature and size of body are part of an ancient inheritance, one which has not been altered by the passage of hundreds or thousands of years." Yet the environmental changes, both as regards housing, hygiene (personal and public), the quantity and quality of food, during this long span of years are prodigious.

So far I have been speaking of the average ultimate stature of the adult. The evidence, $I$ think, is plain that it is largely dominated by racial or hereditary characteristics which, if they can be altered at all, must be altered extraordinarily slowly. When, however, we turn to the consideration of the rate of growth in stature, the phenomenon characteristic of the young, we are faced with quite another problem. There is no doubt that a faulty diet may be a most potent agent in inhibiting growth in general. The experiments of Mendel and Osborne and many later workers are quite clear on this point. But the evidence is equally clear that this power to grow is only inhibited, not destroyed. The inhibition may even be of very long duration. The urge to grow in the young is as strong as life itself. Further, the capacity to reproduce is not lost when growth is inhibited nor is the capacity to provide milk suitable for the normal growth of the young despite the faulty diet consumed by the mother. The growth capacity of the young from such mothers is not affected, for if after weaning they are put on a suitable and adequate diet they grow at the normal rate. Moreover, it must be noted that all the evidence goes to show that although it is easy to inhibit increase in body weight by adverse environmental conditions it is difficult to check the persistent growth of skeletal structure.

\section{Factors in Limitation of Growth}

It is probably, one might almost venture to say certainly, true that one of the most potent factors in limiting the growth of children is either absolute lack of food or the consumption of food qualitatively inadequate. Still, if it be admitted that inadequate food is an important causal factor there are other factors, such as faulty housing, lack of exercise, lack of sleep, etc., which play contributory parts. For instance, some very interesting Glasgow data on the growth of school children have been put forward to show the apparent close relation between growth and the size of the house occupied by the parents. 
It is possible to speed up the rate of growth in the underfed child both in height and weight; it is possible even to alleviate or cure malnutrition, but the height ultimately attained will be, in general, that predestined for the particular individual. As Deniker wrote:

"The primordial characteristics of race seem always to get the upper hand, and the modifications produced by environment can alter the stature of the race only within very restricted limits. The miners of a high stature like the Scots, for example, will be still taller than the individuals of the well-to-do classes in, for example, Spain or Italy, and much more so than those of Japan. Stature is truly, then, a character of race, and a very persistent one."

\section{Food Not the Only Factor in Good Nutrition}

My contention, then, is that without in any way detracting from the value of food as an all-important factor in good nutrition, it is impossible to accept food as the only factor. Food alone will never achieve the results claimed and apparently expected. Food intake, no matter how abundant and well selected, without, for example, exercise or adequate sleep, will not determine the state of good nutrition. It is relatively easy to develop eusitia (well-fed-ness), but a much more complex and intricate problem to develop eutrophia (good nutrition). It is probable that on the whole it is easier to make up early deficiencies of diet than deficiencies of physical culture in the broadest sense of the term.

I repeat, I do not desire to belittle the importance of food or to suggest for a moment that many of the diets in common use are beyond criticism. Unfortunately we have had ample evidence that many of the present-day diets leave much to be desired. Far too often it is stated, more often perhaps assumed, that the defective diets are solely the product of lack of means. It is common knowledge, knowledge confirmed for me at least by our dietary surveys, that frankly bad diets can be found in households not in the receipt of the lowest incomes. It would, on the other hand, be simply the height of folly to assert that income shortage is never to blame in whole or in part.

\section{Diets and Budgets}

The question is often asked why, if the needs of the organism be known, some body of experts does not sit down and work out the cost of such provision. If the assumption be made, and it is only an assumption, that we know (a) the fundamental needs of the human organism, and $(b)$ the sources from which these needs may be completely satisfied, it would seem to most people to require but a simple sum in arithmetic to solve the problem of the relation of an adequate diet to the family budget. But unfortunately in practice the solution is neither easy nor simple. It is not how much money is spent on food but what is obtained with the money spent and how the purchases are used which counts. Acaciemically it is perfectly easy to devise simple yet, so far as our knowledge gces, complete diets which will satisfy all needs at a relatively low cost, but, again unfortunately, the majority of human beings are not content, like many of the domesticated animals, to live day in day out on a monotonous diet. The difficulty is that the majority of mankind want and demand change and variety, a demand which in the end increases cost. There is, indeed, no hardand-fast scientific solution of the practical problem. There are too many variables, and not the least of these are those which are associated with the likes and dislikes, the traditional beliefs, customs, and conventions of the consumer. It must not be forgotten that there is a definite psychological aspect to the problem of diet.
We have only to turn over the pages of the recent report of the International Institute of Agriculture to find evidence for the diversities which exist in dietary demand. If race $A$, which consumes $73 \mathrm{lb}$. of meat per head per year, is fit and healthy, is race B, which eats $236 \mathrm{lb}$. of meat per annum, overfed and pathological? Or is race $\mathrm{C}$, which consumes 6.71 bushels of wheat per head per year, leading a physiological life when race $D$ manages to get along on 2.5 bushels per head per year? Further, even within the limits of a single country like our own, for various reasons there is a very wide range in the prices of ordinary standard foodstuffs. For which consumption of meat or wheat, for which price level, are we expected to budget ; and are we to budget for the good housewife and cook or the bad and careless one?

I am convinced that a mere increase in wages or allowances will not solve the question of defective diets. There is no guarantee that the extra money, if given, will be spent in a proper fashion. As Professor Forrester said in a recent address, when speaking on the relation between incomes of the relatively poor and prices,

" increase in purchasing power would only be partly spent in remedying deficiencies in dietary, since people would attempt to increase their satisfaction on all items in the standard of living and not merely on food. It would require some specific measure of public intervention to secure the whole of the increase for food expenditure."

Moreover, even if it were all spent on food, there would be no guarantee that the proper materials would be purchased and utilized to the best advantage. The solution, where immediate action is required, would be the provision of cooked meals, as is done in schools. But this is no permanent solution. Although I do not believe that the average working-class housewife merits the damning indictment of the Frenchman Siegfried, in his book England's Crisis, it is probably true that as compared with the average Frenchwoman of her class she does not have their "sense of or delight in economy." "Do not imagine," he concluded, "that the French workman, though he receives less than half as much money [as the English workman] lives only half as well."

\section{The Need for Education}

Improved education on what can be done in the way of dietary is badly required-education in budgeting, marketing, and cooking. Too often it is assumed these are easy arts to practise, that every woman receives them as inborn gifts. On the contrary, they are difficult arts, only to be acquired by patience and time. The education must be such that it is suited to the needs, skill, and intelligence of those who require assistance ; and, as the experience of such institutions as welfare centres clearly shows, the majority of the mothers are eager and willing to be taught. We are not an imaginative people where food is concerned, and the food shopping list is very limited. Many of the really valuable foodstuffs are neglected. If it be well to include in the diet a good supply of first-class proteins why is greater use not made of fish? Why is herring, one of the most excellent of protective foods, relatively neglected? Why is more use not made of cheese, of liquid skim-milk where available, or of dried skim-milk? Much of the modern cereal foodstuffs could with great advantage be replaced by potatoes, which provide vitamins $B$ and $C$, iron, and readily available calcium and phosphorus. The British Medical Association has made an excellent start with the recent publication of its small book, Family Meals and Catering. 


\section{Concluding Remarks}

In conclusion I should just like to say a word regarding those who do not require to consider every penny spent on food. Faulty dieting is not uncommon among this class, where appetite is, as a rule, the sole dictator of intake. It is true that certain workers have stressed following the dictates of appetite, but it is very difficult to say whether this is always a sound line or no in the human being. There is ample evidence that it is an effective guide in the case of certain animals like pigs, dogs, and rats, which are not pampered and are given a free choice in the selection of their food. There is no question about the fact that apparently perfectly normal human beings exhibit wide variances in their food preferences, based often, I believe, on real but probably more often on imaginary needs. Again I emphasize the point that in this question of food the problem is frequently as much psychological as physiological. "Better a dinner of herbs, where love is, than a stalled ox and hatred therewith" is very sound doctrine. The great danger is that people develop a pathological interest in food, that they become food-conscious due to the superfluity of ill-advised chit-chat concerning the virtues or evils of this or that article of diet. It is infinitely more profitable to follow the advice,

\section{“Eat all kind Nature doth bestow; It will amalgamate below If the mind says it shall be so. But if you once begin to doubt The gastric juice will find it out."}

\section{$=$ \\ THE “DISPOSITION" AND THE SPECIFIC ALLERGEN IN ASTHMA, HAY FEVER, AND OTHER ALLERGIC CONDITIONS}

BY

\section{E. M. FRAENKEL, M.D.}

The phrase "allergic disease" means no more as a diagnosis than the terms "infectious disease" and "metabolic disease." Three alterations in the normal behaviour of the tissues are considered to be characteristic of allergic conditions and reactions. The most striking of these is the constriction of the smooth muscles, such as takes place in the bronchial spasm of asthma, in the spasm of the bowel in spastic colitis, or in the vascular spasm that is presumed to take place in migraine. The second alteration is a localized exudative increase in the water content of certain tissues, such as occurs in the skin in Quincke's oedema and in the mucous membranes in rhinitis and other catarrhal conditions. The third alteration that is often present is a generalized or localized increase in the eosinophils. In most cases a combination of all three of these conditions is characteristic.

\section{The Allergic Reaction}

This type of so-called "allergic reaction," particularly the constriction of the smooth muscle fibres, is an effect that can be produced by irritation of the parasympathetic nervous system. It is therefore conceivable that anything and everything causing such an irritation would result in the same complex of symptoms and that everything capable of counteracting this irritation could be used as a therapeutic or prophylactic agent. The parasympathetic irritation might be due to a reflex action from a special area. An abnormally high irritability of an area, as in the conjunctivae and the nasal, bronchial, and intestinal mucous membranes, might therefore be responsible for the onset of reactions induced by irritants harmless to less sensitive parts or persons. On the other hand, it shows that the hypersensitivity towards irritation at one spot does not usually mean that there exists a general hypersensitivity of all tissues of the body, and it is in this way that the localization of the irritability may be produced.

The irritability of the parasympathetic ncrvous system, however, depends on such general metabolic factors as the balance of potassium and calcium salts in the mineral content of the tissues. The calcium acts as a stabilizing factor ; in a similar way other metabolic factors may act as sympathetic or parasympathetic irritants, and others may prevent this irritation. For example, such endocrine products as pituitrin and adrenaline counteract the irritation of the parasympathetic by counter-irritation of the sympathetic, whereas a drug like atropine protects the parasympathetic from irritation. It may thus be understood that the constitutional behaviour of different types of patients at different periods of life-as at puberty and during the menopause-or while subject to endocrine disturbance, can so alter their irritability that they become hypersensitive towards otherwise innocuous irritants. The regulation of the sympathetic nervous system by the higher centres and by psychic factors may work in both directions, causing either an increase or a decrease in the irritability. Cures brought about by suggestion therapy cannot therefore be used as proof of the psychological origin of the irritability.

\section{Disposition Towards Allergic Irritation}

Irritability of the sympathetic nervous system cannot be neglected in the investigation and treatment of allergic patients. It is the variation in the conditions mentioned above that we may call the disposition of the patient towards specific allergens. A change in both local and general irritability may be brought about by a variety of factors. To these is added the factor of the external irritant, the so-called allergen. A number of allergens are so powerful that they produce an allergic condition in all persons exposed to their action. These are followed by a number ranging in potency down to those so weak that they give rise to symptoms in only a few particularly susceptible persons. Hay-fever pollen, for example, affects about 1 per cent. of the population of large towns, whereas it has been found in Switzerland that the country people are affected only to the extent of about 0.2 per cent. of the population. This shows clearly that the same allergen has a different effect upon a population under different conditions, and that the disposition plays a definite part in allergic diseases.

The mechanism of an allergic reaction is probably similar to that of an anaphylactic shock or to that of parasympathetic irritation in general. It has been shown by Dale and others that both anaphylactic shock and nervous irritation are either followed or caused by the formation of acetylcholine in the tissues, acting in a similar way to histamine in causing contraction of the smooth muscles. It is not yet quite clear whether these or similar compounds can be split off from the supposed allergen, or whether, in the case of allergic reactions, they are produced by the cells of the subject under the influence of a specific parasympathetic irritation.

Theoretically any type of irritation, physical or chemical, acting in conjunction with the factors described above, could give rise to any one of the reactions known as allergic. In point of fact the well-defined allergens 